\title{
SOFTWARE GEOGEBRA- GEOMETRIA PARA OS SURDOS
}

\section{ARTIGO ORIGINAL}

ANTUNES, Maria De Fatima Nunes ${ }^{1}$

ARCARI, Inedio ${ }^{2}$

ANTUNES, Maria De Fatima Nunes. ARCARI, Inedio. Software GeoGebraGeometria para os surdos. Revista Científica Multidisciplinar Núcleo do Conhecimento. Ano 05, Ed. 08, Vol. 05, pp. 64-71. Agosto de 2020. ISSN: 2448-0959, Link de acesso: https://www.nucleodoconhecimento.com.br/educacao/softwaregeogebra

\section{RESUMO}

As pessoas com deficiência, as quais convivemos todos os dias, estão presentes na escola, em especial na sala de aula. Entre eles, temos o estudante surdo, que se comunica em Libras, sua língua natural. Neste sentido, o intuito deste artigo é apresentar que além das Libras existem tecnologias que estão a favor do surdo, entre elas, destacamos o Software GeoGebra, um programa que pode ser baixado gratuitamente na internet. O objetivo geral deste estudo é indicar e mostrar o GeoGebra, como uma ferramenta que pode proporcionar ao estudante surdo uma interação mais dinâmica e visual no ensino das figuras geométricas através do Tangram. Para isso, sua metodologia, trata-se de um estudo bibliográfico, pesquisas em sites da capes, livros, revistas e Google Acadêmico. Considera-se que, o GeoGebra proporciona, na disciplina de matemática, nos anos finais do Ensino Fundamental, um ensino mais dinâmico e visual das figuras geométricas através da montagem do Tangram. Assim, o estudante surdo, tem uma interação com o

\footnotetext{
${ }^{1}$ Mestra em Ensino de Ciências Exatas. Pedagoga.

2 Doutor em Engenharia Elétrica e Mestre em Matemática.
} 
GeoGebra quase que em tempo real, ou seja, as respostas das atividades de Geometria serão quase instantâneas.

Palavras-chave: Surdo, GeoGebra, libras, geometria.

\section{INTRODUÇÃO}

A educação especial, é uma temática que merece um estudo mais aprofundado, pois, trata-se, de uma demanda que está inserida na educação e ainda se encontra com muitas lacunas, a ser estudado pelos professores que atuam nesta área. Neste caso, apresenta-se um estudo, sobre o surdo e o GeoGebra, focando a visualização no Software através do Tangram.

Desta forma, cumpre informar que, por atuar na educação inclusiva, fato que motiva um estudo bibliográfico sobre o potencial que o GeoGebra tem em relação ao ensino da Geometria (Tangram) na disciplina de Matemática com os alunos surdos. Dito isto, as tecnologias têm sido subutilizadas na disciplina de Matemática, em especial na Geometria. Muitas vezes, os professores de Matemática, se prendem muito a materiais manuais como quadro branco e pincel, deixando de trabalhar com recursos tecnológicos, em especial com estudantes surdos.

Ademais, acredita-se que as formas geométricas estão presentes na vida do aluno, independente do espaço no qual ele está inserido. Uma vez, que, o surdo tem como seu primeiro artefato a visão "os olhos", pode desenvolver junto com a sua língua materna, as Libras, o ensino da Geometria no GeoGebra. Sendo assim, demonstrar o GeoGebra, como uma ferramenta que pode proporcionar ao estudante surdo uma interação mais dinâmica e visual no ensino das figuras geométricas através do Tangram.

Partindo desses pressupostos, para o estudo da temática, faz-se necessário um estudo bibliográfico, acessando no site da Capes, Livros, Google Acadêmico, revistas que serviram de amparo teórico. Sendo dividido em dois momentos: o ensino da 
Geometria na Segunda Fase do Ensino Fundamental e o GeoGebra e o visual constituíram a revisão teórica.

\section{DESENVOLVIMENTO}

O desenvolvimento está dividido em duas subseções. Na primeira, intitulada "O ensino da Geometria na Segunda Fase do Ensino Fundamental", relata os autores que enfatizam a importância da Geometria em nossas vidas, uma vez que ela está presente em todo espaço, especialmente na sala de aula. Sendo assim, faz parte dos conteúdos de Matemática do 6ํan ano do Ensino Fundamental conforme previsto na Base Nacional Comum Curricular (BNCC). Na segunda, discorre sobre o Software GeoGebra e o visual, que se apresenta como um programa de suma importância para trabalhar a Geometria com estudantes surdos que são visuais. Esse Software foi criado em 2001 por Markus Hohenwarter com o propósito de facilitar o ensino e a aprendizagem na área da Matemática.

\subsection{O ENSINO DA GEOMETRIA NA SEGUNDA FASE DO ENSINO FUNDAMENTAL}

Ao andarmos diariamente em diferentes locais, ruas, escolas, supermercados, lojas, entre outros ou navegando nas tecnologias, normalmente, não percebemos que estamos atrelados à Geometria. De fato, ela se faz presente nas casas, desenhos nas paredes, carros, vestimentas, natureza, etc., acompanhando-nos nas diversas situações do cotidiano. Cercado pela Geometria,ser humano sempre se movimentou de um local para outro, levando-o a perceber e reconhecer o seu próprio espaço. Nessa perspectiva, Muniz afirma que

[...] a Geometria aparece inicialmente atrelada às necessidades de resolução de problemas para demarcar a terra, prever o estoque de água e construir instrumentos de trabalho. Em suma, os conceitos geométricos surgem como ferramentas para que o homem aja racionalmente no processo de transformação do seu mundo (MUNIZ, 2004, p. 82). 
Segundo Muniz, é necessário entender que a geometria sempre existiu em qualquer espaço, como em demarcação de terras, capacidade de volume de uma caixa e demais atividades executadas pelo homem. Porém, a este cabe transformá-la e usála a seu favor. Conforme Grando,

[...] a origem do desenvolvimento da Geometria nos primórdios, com o homem primitivo, podemos imaginar que 0 conhecimento das configurações do espaço, formas e tamanhos tenham se originado, possivelmente, com a capacidade humana de observar e refletir sobre os deslocamentos, com a construção de estratégias de caça e colheita de alimentos, com a criação de ferramentas e utensílios, visando satisfazer suas necessidades básicas. Ao fixar moradia, com a divisão do trabalho, outras necessidades foram surgindo e a produção do conhecimento geométrico se ampliando. A necessidade de fazer construções, delimitar a terra levou à noção de figuras, curvas e de posições como vertical, perpendicular, paralela (GRANDO, 2008, p. 7).

De acordo com Grando (2008), o homem foi aprimorando os seus conceitos baseados nas próprias experiências do cotidiano e no conhecimento empírico, fazendo experimentos e investigações - neste caso, pesquisadores que estudam a Geometria, hoje presente nos currículos das escolas. Cabe, assim, ao professor, a tarefa de inserila no seu planejamento e garantir a sua execução em todo o Ensino Básico, seja na educação de jovens ou de adultos, incluída a Educação Especial.

Embasada nesses autores, resolvi desenvolver a prática nos Anos Finais do Ensino Fundamental na área da Matemática, mais especificamente no 6oano. Nessa área, podem ser trabalhadas várias unidades temáticas; entre elas, a geometria e os objetos de conhecimento, que, conforme a BNCC são:

[...] plano cartesiano: associação dos vértices de um polígono a pares ordenados, Prismas e pirâmides: planificações e relações entre seus elementos (vértices, faces e arestas), polígonos: classificações quanto ao número de vértices, às medidas de lados e ângulos e ao paralelismo e perpendicularismo dos lados, construção de figuras semelhantes: ampliação e redução de figuras planas em malhas quadriculadas, construção de retas paralelas e perpendiculares, fazendo uso de réguas, esquadros e softwares (BRASIL, 2015, p. 304).

Esses conteúdos apontados pela BNCC (BRASIL, 2015) são objetos de conhecimento que o professor de Matemática precisa incluir em seu planejamento. De fato, ele [0 
conhecimento] é indispensável aos alunos, principalmente quando atrelado ao bemestar da sociedade contemporânea e à formação de cidadãos críticos, cientes de suas responsabilidades sociais.

Nesse contexto, é função do professor, por meio da aplicação de tais conteúdos, direcionar seus discentes a escolherem caminhos que os levem à resolução de problemas do seu cotidiano. De fato, o aluno do 60 ano do Ensino Fundamental precisa desenvolver as suas competências na área da Matemática, sendo que, entre as oito, a Geometria ocupa a terceira posição. De acordo com a BNCC, o estudante está a caminho de

[...] compreender as relações entre conceitos e procedimentos dos diferentes campos da Matemática (Aritmética, Álgebra, Geometria, Estatística e Probabilidade) e de outras áreas do conhecimento, sentindo segurança quanto à própria capacidade de construir e aplicar conhecimentos matemáticos, desenvolvendo a autoestima e a perseverança na busca de soluções (BRASIL, 2015, p. 269).

Além de o aluno entender os conteúdos da Matemática de maneira significativa, é importante que ele saiba estabelecer um elo com as demais áreas do conhecimento, como as Linguagens, as Ciências da Natureza e as Ciências Humanas, pois a Geometria abrange um campo amplo no contexto do estudante. Vários caminhos se abrem para resolver os problemas que aparecem no dia a dia, como a sua própria sobrevivência e o manuseio dos instrumentos, elementos necessários à execução de atividades manuais e intelectuais (BRASIL, 2015).

\subsection{O GEOGEBRA E O VISUAL}

Nos últimos anos, com frequência, o termo GeoGebra tem sido mencionado. Mas, afinal, qual o significado desse vocábulo? E para que serve? Se pesquisarmos, descobriremos que é um Software de Matemática gratuito e que sua primeira versão foi criada por Markus Hohenwarter, em 2001, no término de sua dissertação de mestrado em Educação Matemática e Ciências Computacionais na Universidade de Dalzburg Áustria. Ele continuou pesquisando e explorando esse Software durante o 
desenvolvimento do projeto de sua tese de doutorado em Educação Matemática (GETTYS, 2009).

Por meio desse recurso, é possível trabalhar e explorar a Matemática em todos os níveis de ensino. Em relação aos conteúdos, destacam-se a Geometria, tabelas, gráficos, estatística, cálculos, álgebra, que podem ser desenvolvidos em todas as etapas do Ensino Básico, instigando o aluno a buscar o conhecimento por meio da disciplina em questão. Esse programa pode ser encontrado facilmente em sites de busca ou no endereço www.GeoGebra.org. Possui como default uma tela inicial, uma barra de ferramentas, uma janela de visualização, uma de Álgebra e um campo de entrada conforme descreve a Figura 1.

Figura 1: Tela inicial do GeoGebra versão 6

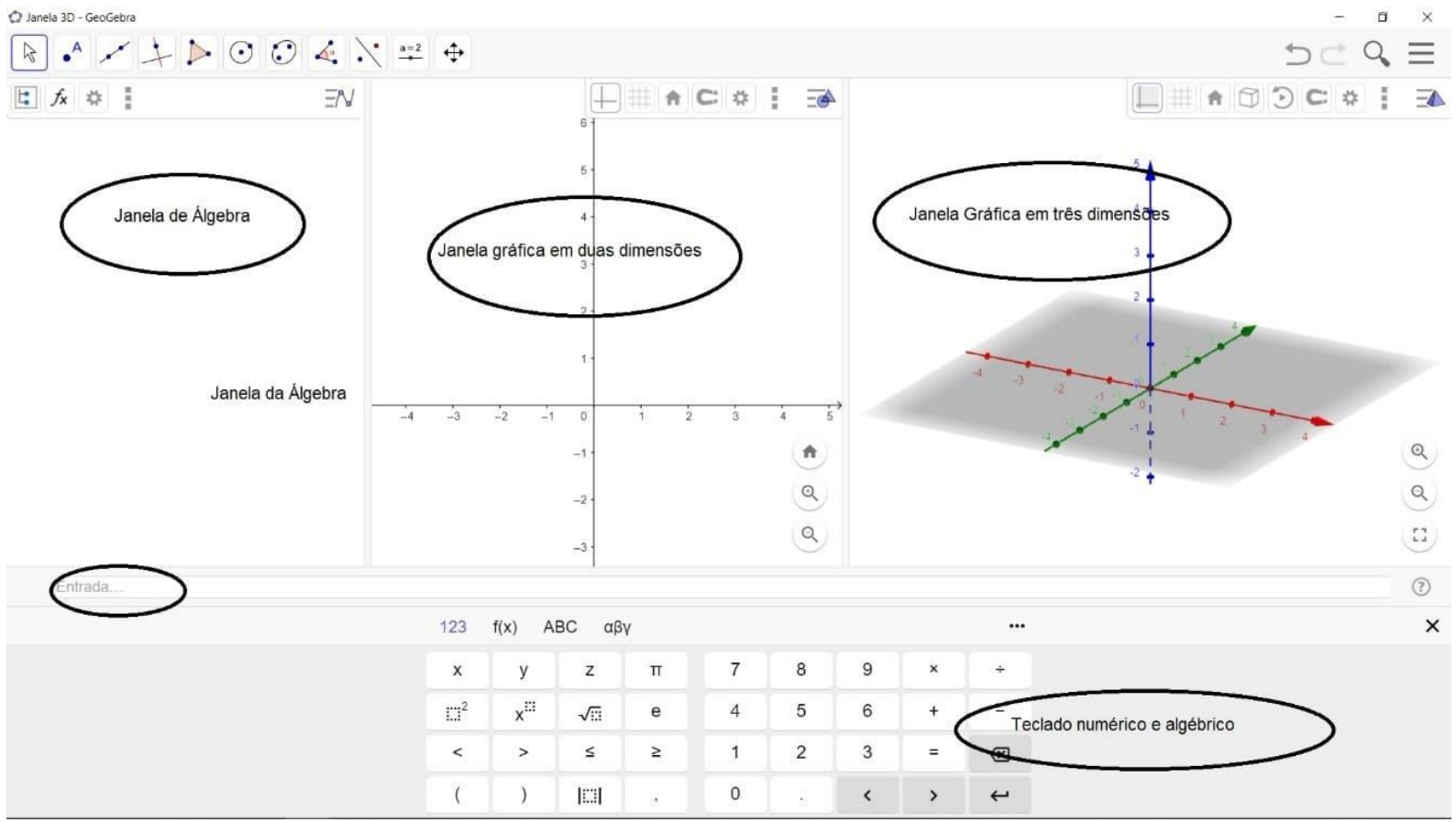

Fonte: Autores (2019).

O GeoGebra é uma ferramenta interativa e dinâmica para o ensino da Geometria e da Álgebra. Os recursos tecnológicos por ele oferecidos permitem ao aluno investigar e testar as atividades de Matemática em tempo real. O discente interage com o próprio Software realizando as atividades no ambiente virtual desde que estejam voltadas à 
Geometria e à Álgebra (MORAES, 2012). Pelo fato de esse programa apresentar relações de interação entre o sujeito e o conteúdo, é importante informar que:

O termo dinâmico refere-se às ideias de movimento e às mudanças que permite que os alunos visualizem as construções realizadas, facilitando a compreensão do comportamento geométrico dos elementos envolvidos nesse processo (SCHATTSCHNEIDER; KING, 1997, p. 58).

No excerto, os autores afirmam que a utilização do GeoGebra faculta ao aluno uma participação ativa e crescente nos conceitos do conhecimento matemático, especificamente a Geometria. É um programa que contém as ferramentas necessárias de um Software de Geometria Dinâmica, pois

[...] permite construir figuras geométricas planas e espaciais e deformálas, mantendo suas propriedades iniciais; - Possibilita a criação de novas ferramentas e adicioná-las na barra de menu, incrementando assim suas funções; Permite que seus arquivos sejam facilmente compartilhados e armazenados; - O campo de entrada de comandos (digitação) é o espaço reservado para a inserção dos comandos desejados; A Barra de Menu possui 8 opções de ícones, possibilitando diversas opções para manuseio do Software; - A Barra de Botões Padrões apresenta várias opções de ferramenta que podem ser visualizadas rapidamente clicando sobre a opção desejada; - A área de trabalho apresenta as construções realizadas após as operações necessárias; Cada objeto criado na Zona Gráfica tem também uma representação na Zona Algébrica (ARAUJO, 2017, p. 34).

Sendo assim, o Software GeoGebra se caracteriza como um recurso tecnológico que possibilita ao aluno surdo interagir com os conteúdos da Geometria de forma lúdica e instantânea. Neste momento, ouso afirmar que alguns conteúdos aprendidos tradicionalmente com o uso da lousa e do giz podem ser otimizados e intensificados por meio desse recurso, tornando a compreensão mais prazerosa uma vez que a visão da pessoa surda tem a função de um quarto sentido: compensar o da audição, que Ihe foi privado (STROBEL, 2008). 


\section{CONSIDERAÇÕES FINAIS}

Este artigo teve, como objetivo geral, demonstrar o GeoGebra, como uma ferramenta que pode proporcionar ao estudante surdo uma interação mais dinâmica e visual no ensino das figuras geométricas através do Tangram.

Posto isso, algumas considerações, são importantes destacar, em relação a temática estudada, que além da Libras, temos as tecnologias que aliadas do surdo, em específico o GeoGebra. Diante disso, o GeoGebra pode proporcionar ao estudante surdo, um elo, quase que, em tempo real ao desenvolver alguma atividade que esteja voltada as figuras geométricas presentes no Tangram. Essa interação poderá acontecer pelo fato de o GeoGebra ser uma ferramenta dinâmica e fácil de ser manipulada pelos estudantes. Acredita-se que além da Libras, o Software é um grande aliado do surdo, pois, os surdos se comunicam com os olhos conforme já relatado neste trabalho.

Em consonância, o Software é uma ferramenta de suma importância para o surdo aprender, de forma instantânea, os conteúdos de Matemática, especialmente a Geometria. Ademais, o não uso das tecnologias nas aulas de matemática, pode contribuir para o desinteresse dos alunos pelo ensino da Geometria, ou seja, quando os conteúdos são transmitidos pelo modelo tradicional.

Em suma, nesta caminhada, acredita-se que o uso das tecnologias favorece o ensino da Geometria e, por conseguinte, a aprendizagem dos alunos, em especial as figuras geométricas contidas no Tangram. Porém, antes de desenvolver qualquer atividade, o professor precisa fazer um bom planejamento e estudar o GeoGebra, ações necessárias para ensinar algo a alguém.

\section{REFERÊNCIAS}

ARAUJO; Josias Júlio de. O software GeoGebra numa proposta de formação continuada de professores de matemática do ensino fundamental. $2017.155 f$. 
Dissertação (Mestrado Profissional em Educação Matemática) - Universidade Federal de Ouro Preto, 2017.

BRASIL. Base Nacional Curricular Comum (BNCC): documento preliminar. Brasília: Ministério da Educação, 2015. Disponível em: http://basenacionalcomum.mec.gov.br/images/BNCC_El_EF_110518_versaofinal_sit e.pdf. Acesso em 11/05/2019.

GETTYS, T. GeoGebra: free dynamic mathematics software. In: OREGON MATHEMATICAL Association Of Two Year Colleges, 24 $4^{\text {th }}$., 2009. Conference..., Lincoln City: Ormatyc, 2009.

GRANDO, Cláudia Maria. Geometria: espaço e forma. Chapecó: Unochapecó, 2008.

MORAES, R. G. Geometria Dinâmica como alternativa metodológica para o ensino de geometria: experiência em um curso de Licenciatura em Matemática. Dissertação (Mestrado Profissional em Educação Matemática) - Universidade Severino Sombra, Vassouras, 2012.

MUNIZ, Cristiano A. Explorando a Geometria da orientação e do deslocamento. GESTAR II, TP6, p. 80-102, 2004.

SCHATTSCHNEIDER, D.; KING, J. Geometry turned on! Dynamic software in learning, teaching, and research. Washington, D.C.: The Mathematical Association of América, 1997.

STROBEL, Karin. As imagens do outro sobre a cultura surda. Florianópolis: UFSC, 2008.

Enviado: Julho, 2020.

Aprovado: Agosto, 2020. 